\title{
Notes on the vocalizations of Lineated Woodcreeper (Lepidocolaptes albolineatus)
}

Peter Boesman

In the following we briefly analyze and compare voice of the different races of Lineated Woodcreeper (Lepidocolaptes albolineatus). We also try to quantify the extent of any vocal differences using the criteria proposed by Tobias et al. (2010), as a support for taxonomic review. We have made use of sound recordings available on-line from Xeno Canto (XC) and Macaulay Library (ML).

Voice of the different taxa has already been briefly discussed in Rodrigues et al. (2013) (although the primary focus of the paper was rather the description of the new taxon fatimalimae and its genetic relation to the other races).

Five groups are distinguished (note that ranges of the named races differs somewhat from the geographical ranges described in HBW, e.g. birds in E Ecuador belong to duidae, presumably because purely classifying based on morphological characters has lead to errors in the past). About vocalizations, only the following quantified data are given:

Table 1. Summary statistics of song parameters of taxa grouped in the Lepidocolaptes albolineatus species complex.

\begin{tabular}{lccccc}
\hline Taxon & $\begin{array}{c}\mathrm{N}^{\circ} \text {. of } \\
\text { individuals } \\
\text { and songs }\end{array}$ & Nean (st. dev.) & Range & length (st. dev) & pace (st. dev) \\
\hline L. fatimalimae & $8(24)$ & $29.5(4.96)$ & $16-37$ & $2.80(0.46)$ & $10.60(1.58)$ \\
L. albolineatus & $10(42)$ & $28.11(6.08)$ & $17-45$ & $2.38(0.50)$ & $11.79(0.58)$ \\
L. duidae & $13(39)$ & $12.03(4.88)$ & $6-20$ & $2.20(0.58)$ & $5.56(2.39)$ \\
L. fuscicapillus & $7(16)$ & $5.21(1.29)$ & $3-9$ & $2.25(0.58)$ & $2.33(0.24)$ \\
L. layardi & $10(47)$ & $4.68(1.15)$ & $3-7$ & $1.89(0.53)$ & $2.55(0.50)$ \\
\hline
\end{tabular}

If only this table were to be used, than obviously effect size of the mentioned parameters would be very small in between the first 2 and last 2 taxa, as there is only a minor difference ! 

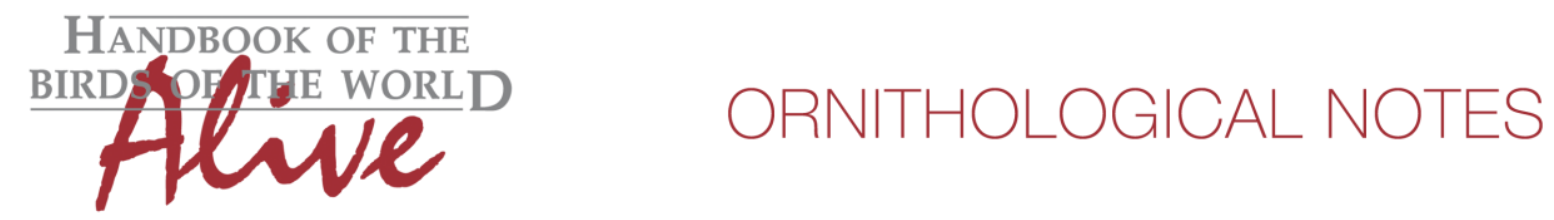

Races fatimalimae and albolineatus have several additional vocal differences however (Fig. 1).

The main ones being:

- Trill accelerates in fatimalimae, not in albolineatus

- Notes become shorter in fatimalimae, not in albolineatus

- Pitch decreases gradually in fatimalimae with an overall drop of c. $800 \mathrm{~Hz}$, on the contrary song of albolineatus typically rises at first and then stays at same pitch.

- Amplitude is high from the start in fatimalimae, in albolineatus amplitude swells in the beginning.
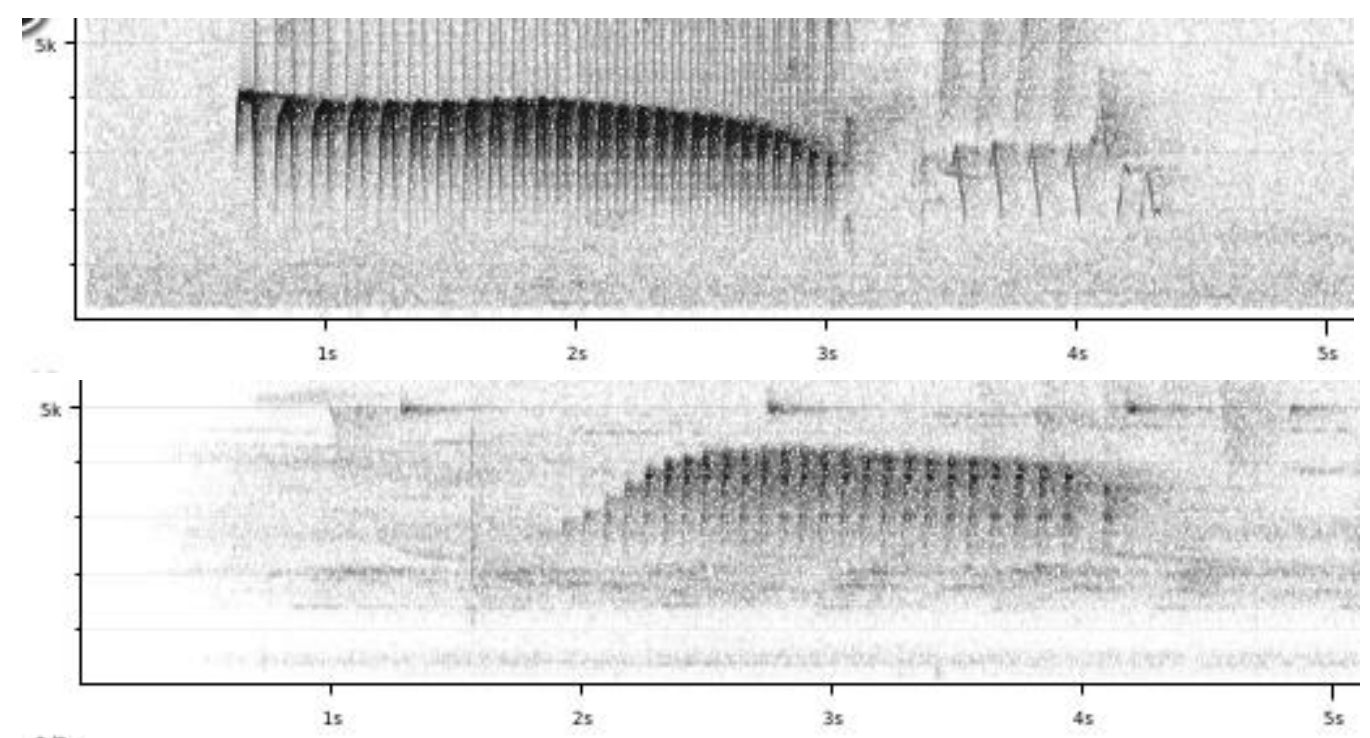

Figure 1: typical song of fatimalimae (above) and albolineatus (below)

Although song of both taxa is similar in number of notes and pace, trill in fatimalimae is accelerating (2-3), notes becoming shorter in length (2-3), and pitch is decreasing steadily vs increasing initially and then constant (2-3), leading to a total vocal score according to Tobias criteria of about 5.

Additional to the differences between duidae (Fig. 2) and albolineatus mentioned in table 1, we can highlight:

- duidae has longer notes (longest note 2-3 times longer than albolineatus)

- notes become shorter towards the end and pace increases in duidae, not in albolineatus

- duidae drops in pitch towards the end, albolineatus rises at first in pitch

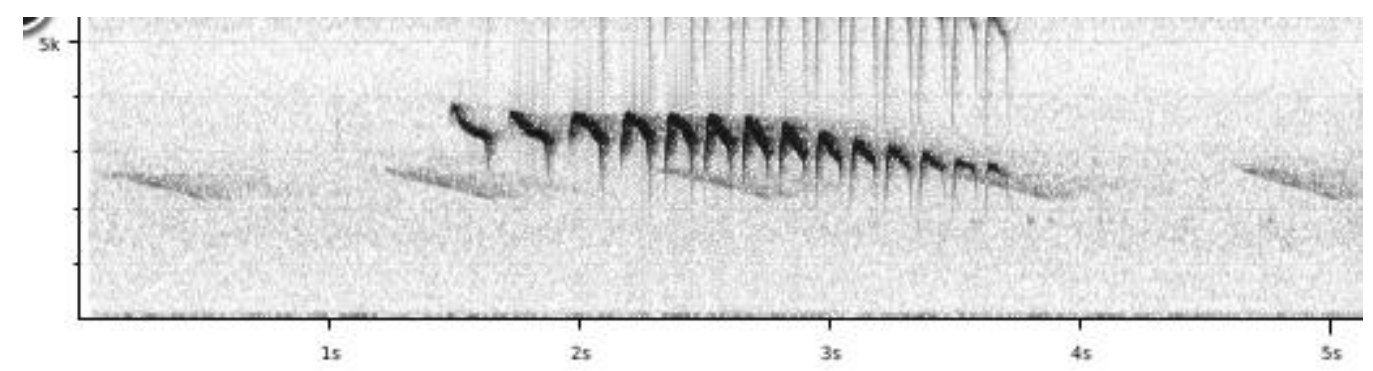

Figure 2: typical song of duidae 

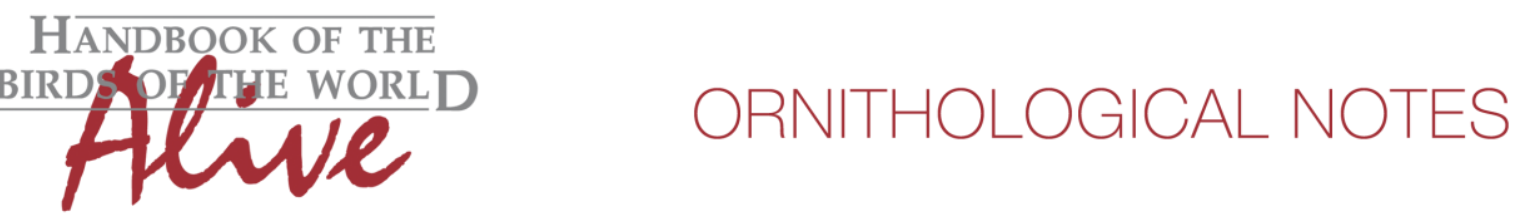

In summary, song of duidae differs from albolineatus by fewer (roughly half as many) notes (3) which are longer in length (3), delivered at a much slower pace (3), which increases (stable in albolineatus; 2), and at the end dropping vs initial rising in pitch (2-3), leading to a total vocal score according to Tobias criteria of 6 . Song of duidae differs from fatimalimae by fewer (roughly half as many) notes (3) which are longer in length (2), delivered at a much slower pace (3), leading to a total vocal score according to Tobias criteria of 6.

When comparing duidae with fuscicapillus/layardi, similar additional differences can be mentioned.

Remains the pairwise comparison of fuscicapillus (=madeirae) versus layardi...

From table 1 it is clear that basic parameters are very similar. The sonograms shown in the paper suggest there is a notable difference between both, something I was not able to confirm when listening to recordings of both races. I looked up the recording of which the paper produced and printed the sonogram (LNS 51900), and used the identical song phrase to produce a sonogram (Fig. 3)
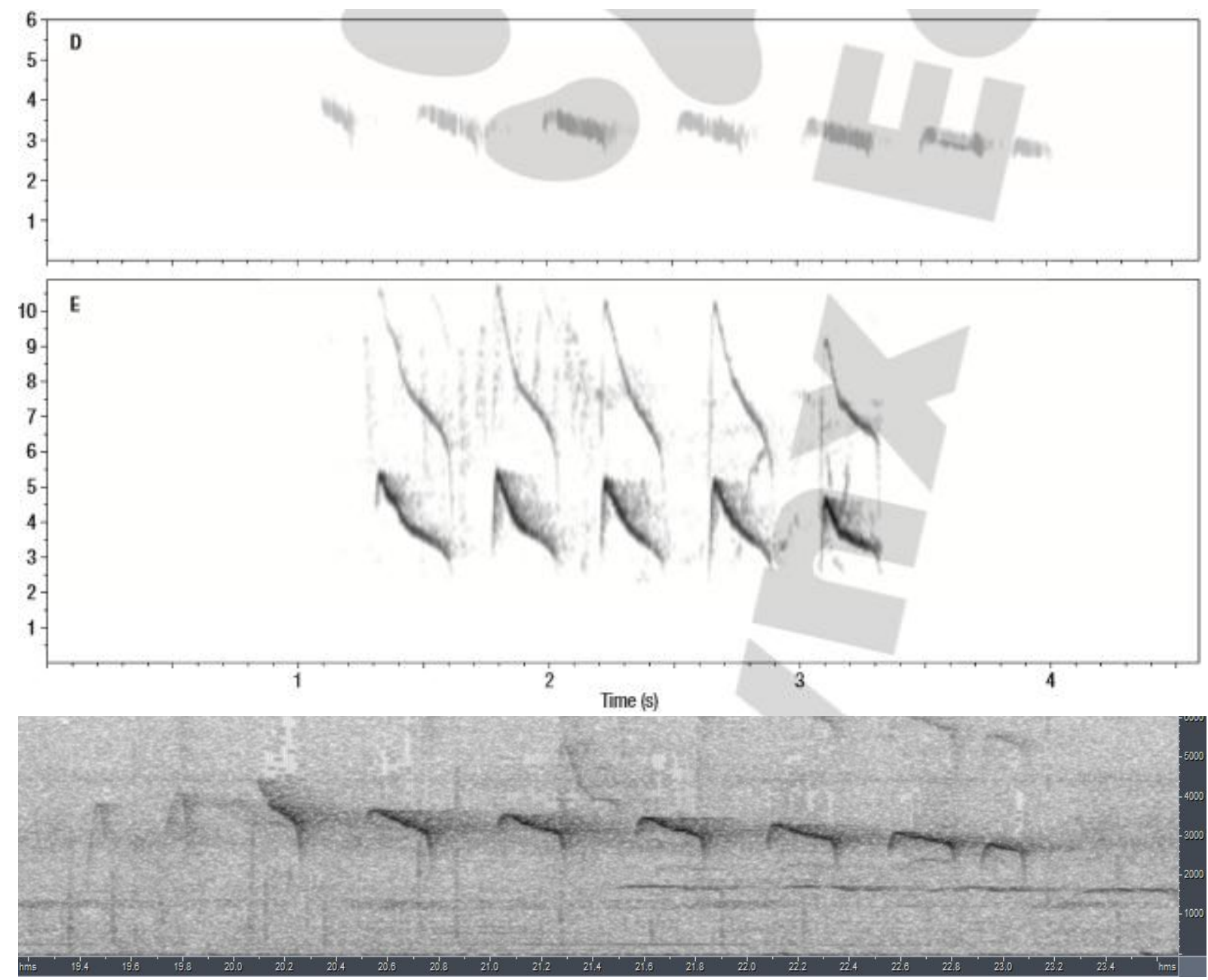

Figure 3: sonograms depicted in Rodrigues et al. (2013) (D: fuscicapillus, E: layardi) and depiction of same fuscicapillus with different energy settings 


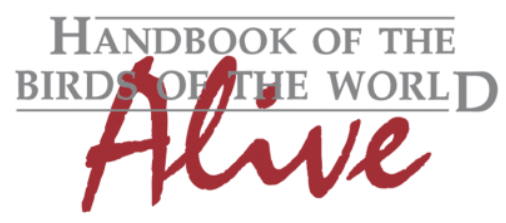

\section{ORNITHOLOGICAL NOTES}

Differences are now clearly smaller, with note shape of first note nearly identical. When looking at sonograms of additional recordings, it is clear that differences are in fact minimal (Fig. 4), to the point that there is no audible difference.
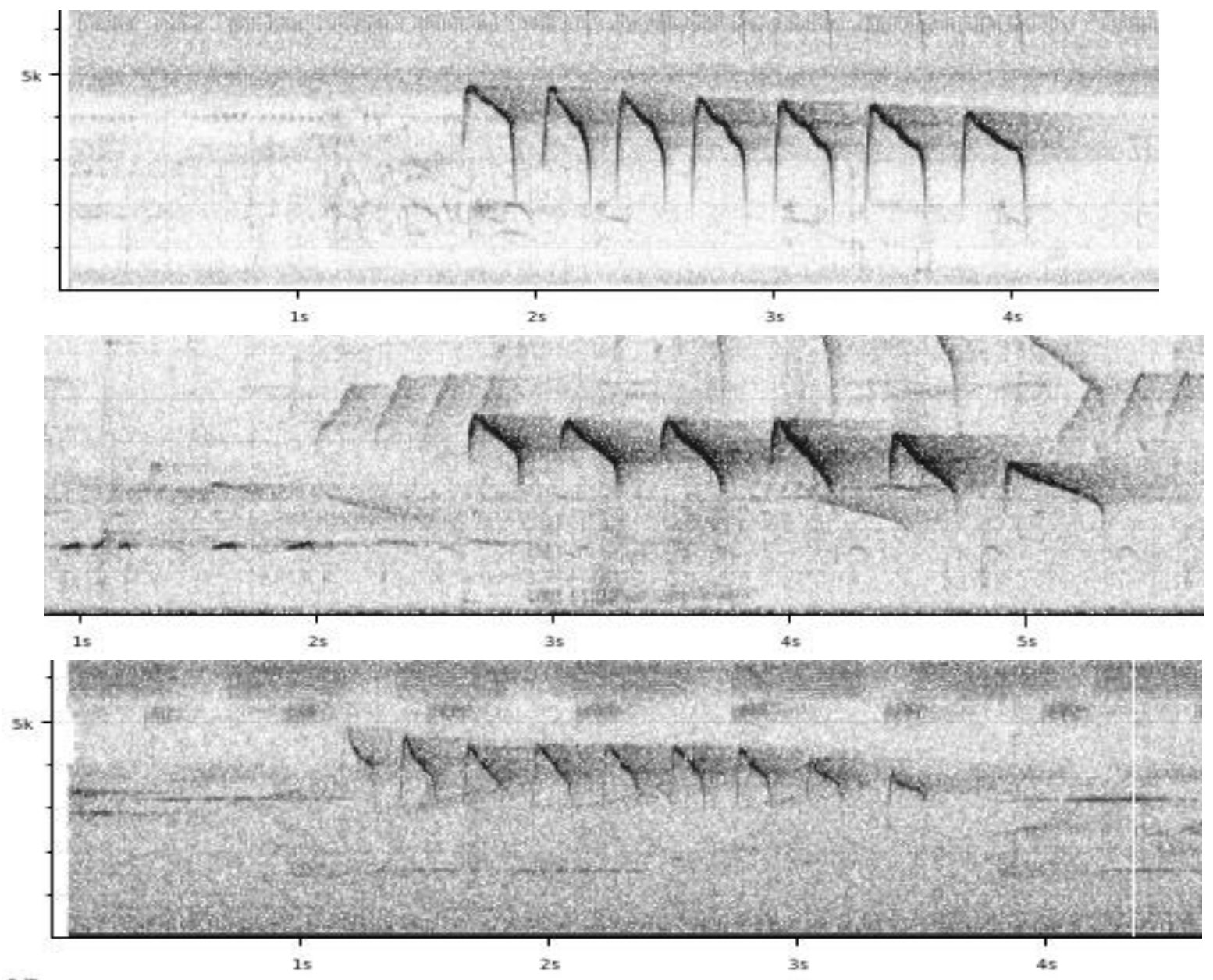

Figure 4: top: fuscicapillus (Borba, XC91467, Jeremy Minns), middle: presumed layardi based on distribution (Rio Cristalino, XC224196, Peter Boesman), bottom: layardi (Pará, XC5694, Sidnei de Melo Dantas)

Based on the available recordings on-line and the information provided in Rodrigues et al. (2013), there is thus no clear indication of any vocal difference between fuscicapillus and layardi.

We therefore conclude that vocally there is a major difference between the following taxa:

L. albolineatus of the Guianas

L. duidae of NW Amazon

L. fatimalimae of SW Amazon

L. fuscicapillus/layardi of the remaining Amazon region 
This note was finalized on 7th April 2015, using sound recordings available on-line at that moment. We would like to thank in particular the many sound recordists who placed their recordings for this species on XC and $\mathrm{ML}$.

\section{References}

Rodrigues, Aleixo, Whittaker \& Naka (2013). Molecular systematics and taxonomic revision of the Lineated Woodcreeper complex (Lepidocolaptes albolineatus: Dendrocolaptidae), with description of a new species from southwestern Amazonia. HBW SV: 248-252.

Tobias, J.A., Seddon, N., Spottiswoode, C.N., Pilgrim, J.D., Fishpool, L.D.C. \& Collar, N.J. (2010). Quantitative criteria for species delimitation. Ibis 152(4): 724-746.

\section{Recommended citation}

Boesman, P. (2016). Notes on the vocalizations of Lineated Woodcreeper (Lepidocolaptes albolineatus). HBW Alive Ornithological Note 84. In: Handbook of the Birds of the World Alive. Lynx Edicions, Barcelona. (retrieved from http://www.hbw.com/node/931978 on 17 July 2016). 